\title{
Using military friendships to optimize postdeployment reintegration for male Operation Iraqi Freedom/Operation Enduring Freedom veterans
}

\author{
Ramon Hinojosa, PhD; ${ }^{1 *}$ Melanie Sberna Hinojosa, $\mathbf{P h D}^{\mathbf{2}}$ \\ ${ }^{1}$ Rehabilitation Outcomes Research Center, North Florida/South Georgia Veterans Health System, Gainesville, FL; \\ ${ }^{2}$ Institute for Child Health Policy, Department of Health Outcomes and Policy, University of Florida, Gainesville, FL
}

\begin{abstract}
Social relationships are important to health outcomes. The postdeployment family reintegration literature focuses on the role of the civilian family in facilitating the transition from Active Duty military deployment to civilian society. The focus on the civilian family relationship may miss other important personal connections in veterans' lives. One such connection is the relationship many veterans have with former military unit members who served with them when deployed. Drawing on interviews with male Operation Iraqi Freedom/ Operation Enduring Freedom veterans conducted from 2008 to 2009, we argue that the members of a military unit, especially during armed conflict, should be considered a resource to help the "family" reintegration process rather than impede it. This research has implications for current reintegration policy and how best to assist veterans transitioning into civilian society.
\end{abstract}

Key words: clinical resources, community reintegration, emotional support, family reintegration, Grounded Theory Method, male, mental health, military friendships, qualitative research, reintegration, social support, veterans.

\section{INTRODUCTION}

The role of social relationships in health outcomes is an area of growing research importance. The Veterans Health Administration (VHA) has begun to encourage research programs that explore the role of family members in veterans' health outcomes, particularly after the deployed veteran has been away from the family for an extended time. Research shows that contentious postde- ployment interactions with civilian family members are linked with poor mental health outcomes [1-3]. However, supportive and emotionally intimate civilian family interactions with the returning veteran seem to protect against mental health problems. Family therapy sessions that include both the veteran and his or her family have been shown to successfully improve returning veterans' mental health outcomes [4-7].

Postdeployment family reintegration literature focuses on the family's role in helping the veteran transition from Active Duty military deployment to civilian society. This focus may miss other important personal connections that affect the veteran's life. One such connection is the relationship many veterans have with former military unit members who served with them when deployed. Former military unit members are typically cited as obstacles to civilian family reintegration [8] because of the emotional

\footnotetext{
Abbreviations: GTM $=$ Grounded Theory Method, IED = improvised explosive device, OEF = Operation Enduring Freedom, OIF = Operation Iraqi Freedom, PTSD = posttraumatic stress disorder, $\mathrm{VA}=$ Department of Veterans Affairs, VHA = Veterans Health Administration.

*Address all correspondence to Ramon Hinojosa, PhD; Rehabilitation Outcomes Research Center, North Florida/ South Georgia Veterans Health System, 1601 SW Archer Road (151B), Gainesville, FL 32608; 352-376-1611, ext 4934l; fax: 352-271-4540.

Email: ramon.hinojosa@va.gov

DOI:10.1682/JRRD.2010.08.0151 
and experiential ties that bind military unit members. However, we argue that these same ties could be used strategically to create a supportive transition from Active Duty to civilian society.

Drawing on interviews with Operation Iraqi Freedom/Operation Enduring Freedom (OIF/OEF) veterans conducted from 2008 to 2009, we propose that the members of a military unit, especially those who participated as a group during a period of armed conflict, should be considered a resource to help rather than impede family reintegration. This proposal has implications for current reintegration policy and for the best way to help veterans transition into civilian society.

\section{Postdeployment Reintegration}

As of December 2009, 179,090 Active Duty (i.e., fulltime) and 71,217 Reserve Component servicemembers were on Active Duty as part of OIF/OEF [9]. In all, about 2,052,405 servicemembers have been deployed to the Iraq and Afghanistan wars [10]. An estimated 2 to 3 percent of the total American population, including family members, has been directly touched by the Afghanistan and Iraq wars.

Postdeployment reintegration is stressful for veterans and their families, and family upheaval is common $[8,11]$. When the family environment is acrimonious, anger, distrust, and alienation can create veteran mental states that contribute to negative mental health outcomes [12]. Posttraumatic stress disorder (PTSD) diagnoses are more likely for those veterans whose family lives are characterized by low levels of expressiveness, low family cohesiveness, and high interpersonal conflict [1-3]. Contentious family relationships are also related to veteran interpartner violence [13], increased rates and severity of child abuse [14], marital dissolution, and divorce [1517]. At the worst, family dysfunction and dissolution are linked to veteran homelessness [18-22].

\section{Reintegration and Former Military Unit Members}

"We few, we happy few, we band of brothers. For he today that sheds his blood with me, shall be my brother ...." [23].

Western culture has long recognized military friendships to be among the strongest relationships a veteran forms. The ancient Greek philosopher Aristotle noted that military camaraderie was essential for dealing with the emotional strains of combat [24]. Research supports the idea that being part of a military unit creates an uncommonly strong bond between military members. Both for- mal military training and military culture are built around the concept of servicemembers developing profound reliance on their comrades [25], and reliance can foster deep friendships. Physical and social isolation, an experience of shared risks, and deprivations of deployment encourage servicemembers to rely heavily on military unit members for social and emotional support, forging strong friendships [25-27]. This sentiment is found frequently in biographies of those who have been deployed to war. The following quote from Eugene Sledge, a Marine who fought on the Pacific Islands of Peleliu and Okinawa during World War II, captures the essence of military friendships:

No matter how bad a situation was in the [Marine] company, it was still home. ... I belonged in it and nowhere else. Most Marines I knew felt the same way about "their" companies in whatever battalion, regiment, or Marine division they happened to be. . . . A man felt that he belonged to his unit and had a niche among buddies whom he knew and with whom he shared a mutual respect welded in combat. This sense of family was particularly important in the infantry, where survival and combat efficiency often hinged on how well men could depend on one another [28].

Friendships are important in creating unit cohesion, how well unit members identify with the unit and support one another. Unit cohesion is a well-established component of combat effectiveness [26]; is linked to psychological resilience in dealing with combat-related stressors, when combined with leadership [29]; and is important in positive mental health outcomes [30-31]. The personal relationships that troops have with one another sustain them emotionally during military stress. These relationships can affect how well servicemembers operate in combat, handle the strains of combat when not directly in the line of fire, and handle the stress of the return to civilian society. Just as spouse and family member relationships provide positive mental health benefits for veterans [32], so, too, do military relationships.

\section{METHODS}

\section{Participants}

The larger study, from which the data are derived, was designed to explore men's experiences with deployment and reintegration. To do so, we interviewed 20 Reserve component and Army National Guard men deployed as 
part of OIF/OEF missions about their reintegration experiences. Inclusion criteria were males in Reserve components (Army, Navy/Marines, Air Force, or Coast Guard) or Army National Guard who served in Afghanistan as part of OEF after October 2001 or in Iraq as part of OIF after March 2003. We recruited a final number of 20 participants for this research. We assigned all participants pseudonyms to protect their identities and use these pseudonyms throughout this article to identify the participants.

We excluded those who had been seriously injured or physically disabled or were in rehabilitation for combatrelated injuries. These men were excluded because most who served in OIF/OEF were not physically injured and because being physically injured and temporarily or permanently disabled exacerbates the family reintegration experience. The stress associated with service-connected injuries and/or disabilities can add significant strain to the already stressful postdeployment family reintegration and would add another dimension to the study of supportive military friendships. While injury- and/or disability-associated issues may be within the scope of understanding the facilitators and barriers to veteran family reintegration, they were outside the reach of the limited financial and personnel resources dedicated to this project. However, we are currently addressing these issues in other projects.

\section{Demographics}

The average age of the men was 27 years at the time of deployment, and ages ranged from 18 to 48 years. Fourteen men were white, five Hispanic, and one African American. The average level of education was 2 years of college (two held high school diplomas with no college, six reported some college, three had an associate's degree, seven a bachelor's degree, and two a master's degree). The average household income at the time of the interviews was $\$ 58,300$; seven men had children under the age of 18 living at home. Two veterans had served in the Marine Reserves, five in the Army Reserves, and thirteen in the Army National Guard. Fourteen men were deployed as part of OIF, three men both OIF and OEF, and three men OEF. Twelve were deployed in 2004-2005, four in 2003, two in 2005-2006, and two in 2006-2007. Only one was deployed to Afghanistan in 2002, and four were getting ready to redeploy after the interviews (in 2009). Of the sample, six men (30\%) reported being in treatment for substance use disorder.

\section{Analytic Approach}

We held in-depth, semistructured interviews between the summer of 2008 and the fall of 2009 and focused on the veterans' deployment and reintegration experiences. We conducted interviews and explored the veterans' experiences with deployment and reintegration. We divided the interview schedule into periods based on the deployment cycle: predeployment, deployment, and reintegration following deployment. The men were asked to recount their perceptions of events within each of the deployment periods, focusing on experiences with family and friends, issues related to leaving and returning to work or school, and general and specific concerns and experiences they had regarding deployment.

For the predeployment period, we asked the veterans the following questions:

1. Tell me about your predeployment activities (work, leisure, hobbies, etc.)?

2. What thoughts did you have when you learned you were being deployed?

3. What did you think deployment would be like?

4. Where do you believe your deployment ideas came from (friends, family, media, personal experiences, etc.)?

5. Tell me about the reaction of your friends (both military and civilian), family, and others?

6. How did you feel about their reactions (can you provide examples)?

7. Was their response what you expected?

8. What concerns did you have regarding deployment?

9. How did you prepare for deployment (prompt: financial, psychological, and family preparations)?

10. How did your family prepare for deployment?

11. What factors made preparing for deployment easier or harder?

12. What advice would you give others being deployed and why?

We then asked questions that focused on the period of deployment:

1. Tell me about your interactions with your family while deployed. What, if any, changes did you notice?

2. How were you able to maintain lines of communication? Any problems?

3. When it came to your family, what factors made being deployed easier or harder?

4. Did family predeployment preparations make being deployed easier or harder? How so? 
5. What family, friendship, or relationship issues arose while deployed?

6. How did you try to resolve them? Were they resolved?

7. Do you feel your deployment experiences have changed how you view the world? How so or why not?

8. How you view your family? Why or why not?

Finally, the questions that focused on the postdeployment, or reintegration, period were as follows:

1. Tell me your thoughts upon learning you were returning home.

2. Was returning home what you expected? Why or why not?

3. What was the hardest/easiest part of returning home? Why or how?

4. Did deployment affect your family relationships? Why, how, or what?

5. What was different or the same when you returned (family personalities, behavior, and habits)?

6 . Were there aspects of your deployment experience that make interacting with family members difficult? Why, how, or what?

7. Easier? Why, how, or what?

8. Did predeployment preparations help with reintegration? Why, how, or what?

9. What made it easier to return to the flow of civilian society? Harder? Unexpected?

10. What were your experiences with returning to work or school?

11. What mental health concerns do you currently have? Anger/emotions? Drinking? Drugs? Trouble sleeping?

A semistructured approach allows participants to freely discuss issues that are relevant to their experiences but are not specifically inquired about in the interview guide. A structured interview guide may have constrained participants' accounts, in effect, limiting the amount, type, or richness of the data [33]. Using a semistructured interview guide supports a Grounded Theory Method (GTM) approach [34]. Consistent with the GTM approach, we adapted successive interviews to include lines of questioning that probed emerging ideas and concepts (such as the importance of family outsiders) in the family reintegration process. The interviews lasted an average 1.5 hours. We tape-recorded, transcribed verbatim, and analyzed all interviews using the NVivo 7 quali- tative data software (QSR International Inc; Cambridge, Massachusetts).

\section{Grounded Theory Method}

A GTM approach methodically organizes unique individual experiences collected during structured interviews into discrete categories that are comparable across properties and dimensions [35], making both commonalities and variations in personal experiences possible to find. Thematic analysis starts with open coding, a process that entails a line-by-line analysis of data to identify common participant experiences. The investigator codes (labels) these themes by identifying key phrases. For example, we coded the interviews for "combat awakening" or the early phase of deployment in which many of the men came to recognize fully the dangers inherent in combat deployment. Phrases such as "I was prepared, but I did not expect it to be like that," "I knew I was a long way from home," or simply "Oh shit," indicated combat awakening.

As themes emerge, a more focused coding process synthesizes data into organized themes that are then densely packed around a core category; the category of combat awakening is part of the process that alerts servicemembers to the value of both their working relationships with other unit members and their friendships. This category of combat awakening was folded into the core category of military friendships through a GTM approach called "axial coding." Axial coding is done so that data properties (i.e., qualities such as the "when," "what," and "how" of veterans' friendships) and data dimensions (i.e., variations or the types of friendships) can be systematically compared across subjects [34]. Throughout the data collection period (2008-2009), we used the GTM approach of the constant comparative method, in which the interview questions we asked of new participants were informed by our ongoing analysis of former participant's interviews, and we continuously compared the new data we collected with the older data. Although military friendships during and after operational deployment were not the primary area of interest in the original project, they emerged as a recurrent theme in the data.

For this study, we read and reread all transcripts and engaged in axial coding to identify material relevant to the veterans' experiences with their military unit mates and other military personnel. We discussed the data and arrived at a consensus interpretation of the coding. This approach strengthened the dependability of the data [36]. 


\section{RESULTS}

We present four subcategories of military friendship and the properties of each subcategory. They are-

1. Transition to war.

- Anticipation.

- Combat awakening.

- Loss of the family.

2. Growth of the military family.

- Recreation.

- Emotional intimacy.

3. Reintegration.

- Hanging on.

- Loss of the military family.

4. Seeking to reconnect with the military family.

- Informal settings.

- Formal settings.

We end with a discussion of the clinical implications for military friendships during the postdeployment reintegration period.

\section{Transition to War}

Transition is commonplace for many servicemembers as they move from a civilian or training environment into the combat zone. From the standpoint of military friendships, the servicemembers' transition is a process marked by the anticipation and excitement of being deployed and then the realization that they are at war. Concurrently, they experience a sense of loss and a growing distance from their families back home. This process enables servicemembers to strengthen relationships with members of their unit.

\section{Anticipation}

The importance of military friendships was evident in the veterans' discussions of how they dealt with the strains of deployment. Many of the veterans who had never been operationally deployed said that they viewed their deployment with anticipation and excitement. They were anxious to get started and put their training to good use. Rohald, a National Guard soldier, said, "I spent all this time doing training. I wanted to see action." He admits, "Some people don't understand," but compares it with someone who trains to become a physician and wants to practice medicine when he or she is done. "I mean, you want to do doctor stuff. So, most of us soldiers and sailors, we join because we want to see something."
Others treated news of their unit's impending deployment as good news. Mario told us-

It was like "wow we're actually gonna be able to do it and to have to do it" and it kind of felt, as a unit, we felt kind of like "wow-they have all these Reserve units to choose from and they chose us!”

\section{Combat Awakening}

The initial excitement of deployment can wear off quickly as military personnel realize the serious implications of deployment. Servicemembers are faced with the immediate risks of war, including small arms fire, mortar rounds, and improvised explosive devices (IEDs). They "awaken" to the idea that they are not as fortunate as they once thought. They now live in a dangerous environment in which frightening and lethal violence is part of the daily landscape. Servicemembers develop a heightened awareness, sometimes referred to as tactical awareness or hypervigilance. This process involves an increased sense that they are not immortal and that they and their comrades could be wounded or killed. They realize that they are stuck in this environment until their tour of duty is up or they are wounded or killed.

Mark's statements capture the essence of his combat awakening. He arrived in Afghanistan at age 18 with a vague idea of war. After a few weeks, his unit moved into the mountains to help set up a forward-operating base. His initial impressions were of the natural beauty of the river valley below. "I am just looking at the mountains and stuff. You know like this is Afghanistan. This is war so then it was like, okay. It was like a good feeling." His attitude toward deployment soon changed. Within days of arrival at the base camp, his unit came under mortar fire.

That's when it got like "oh shit," you know? That was pretty much, I was just [saying to myself] "Man. This is it. This is the real world and this is war." I can remember what was going through my mind. It is another kind of feeling but I can't really explain. It's just you know, I'm in Afghanistan [said with strong emphasis]!

Brad was 22 years old when he was deployed to Iraq as a member of the Army National Guard. His unit was assigned to a forward-operating base where they performed base security. Within his first few minutes at his duty station, the base was mortared. Several rounds landed close enough that the explosions made his ears ring. "I would say that I was scared and you know, everyone was 
scared on a certain level.” He and other unit members realized that Iraq was a dangerous place and his idea of deployment being an adventure outing, which he admits was his first impression of being deployed, was quickly forgotten.

\section{Loss of Family}

Almost at the same time as a servicemember has a combat awakening, he or she realizes that home is far away. The available communications technology, which is better than ever before for deployed servicemembers, is still a pale substitute for being with one's family. As Eddie said about leaving his 1-year-old daughter behind at the airport:

That was the toughest thing. That was probably the toughest thing, more so than leaving friends and family or you know a girlfriend or a loved one; there's, there's nothing, I would say, nothing, probably nothing tougher that I've ever had to do.

The distance also means a loss of most of the family support that many men once had. This loss happens partly out of military necessity; servicemembers are not able to share with their family their whereabouts or casualties, and in many cases, the men do not share the daily terrors of being in a combat zone. Several of the men said they did not want to worry their family members unnecessarily. And if they had shared their concerns, nothing could have been done to allay those fears, short of returning home safely, which they could not do at that time. James, 23 at the time of his deployment to Iraq, said that he was selective in what he told his family.

Every time I did talk to them, which was very few [times], I was like "this is great out here. I don't have no complaints.” You know, I didn’t want them to worry about me, you know.

The restrictions, whether institutional or self-imposed, meant that many men felt the loss of family relationships very early in their deployments.

\section{Growth of Military Family}

With the initial excitement of deployment gone, the servicemembers realized that war is deadly serious and that they were stuck there without family to support them. Many of the men then turned to the men and women with whom they were deployed. Unit members served as surrogate family members. Most men said they grew close to their unit members. Brad stated, "We all got through it through humor and through our camaraderie and friendship," when reflecting on how he dealt with homesickness and realizing that he was at war. And, as with traditional families, the military family fulfilled recreational and emotional intimacy needs.

\section{Recreation}

One type of friendship interaction was shared recreational activities. Military friendships were strengthened through shared activities that, whether by design or accident, helped to take the men's minds off the daily grind of deployment. Most of these activities are common to civilian society, activities such as playing video games together when not on duty, going to the base store to shop together, or dining at the various restaurants within the base. Just "hanging out" and talking about home, work, girlfriends, and/or wives were common. Others, like Don, found innovative ways to pass the time with friends. "You just find crap to do. Like people just make up ridiculous games and just sit around for hours and, uh, throw rocks at the traffic cones.” This mindless activity distracts the men from the boredom of long hours on uneventful duty. These recreational activities take their minds off the anxiety of being at war and may have some therapeutic value, but they are primarily organized to relieve stress and boredom.

\section{Emotional Intimacy}

Another type of friendship interaction is sharing emotional intimacies. These types of interactions can be considered more therapeutic since they fulfilled some of the men's need for emotional intimacy. Several of the men discussed these interactions. Typically, such interactions occurred in the privacy of one's shelter with bunkmates who were close. Most of the men interviewed said they had one or two others with whom they shared their fears and concerns or longing for home. These interactions provided men a ready listener when homesickness threatened to overwhelm emotions or when they had been involved in firefights, IED attacks, or other near-miss experiences. For others, these interactions took the shape of informal group therapy sessions, in which other servicemembers who shared a job or a living space got together off duty to “decompress," "debrief," and "unload."

Ritchie was a 40-year-old Army reservist with 10 years of prior Active Duty service when he was deployed to Afghanistan in 2004. He worked as the emergency room coordinator and helped care for the wounded. The medical support hospital received casualties from both 
Afghanistan and Iraq and served troops and civilians. More than most, Ritchie was an eyewitness to the effects of war. He cared for troops with life-threatening and grievous physical injuries daily and regularly handled the remains of those who died. In a wrenching example, he said-

The doctor or the surgeon would come in and a person would have an amputated foot, but their two bones were sticking out below all the other tissue. And the doc would say, "could you hold this up so I could look at it all the way and see what I'm gonna have to do?” And I think at that point, you stop seeing that piece of a human being as a human being. You know, you have to separate that because you just don't think, my God, you're holding on to what used to be someone's leg. I think you, in that sense, you prepare your mind for what could happen. But otherwise, you really can't until you get there and you know for yourself, what's going on or what's gonna happen.

This is just one of the daily parades of traumatic events that his job entailed. Ritchie was cognizant of the psychological strains of his job and noted that he knew of resources available to help the troops deal with deployment stressors. "I mean we had psych doctors there constantly. But it's funny; we didn't have any kind of counseling after things like this happened." He dealt with such experiences with the support of his military friends with whom he worked:

That we were able to sit down, and right then and there, that was our counseling. You know, we were pretty much in the same tent. Everyone worked in, worked in different aspects, from me working in the ER [emergency room] to one person working for the computer, um, uh, fixing computers, to another person working on our vehicles. So we had a, a vast array of different people just within our own sleep tent. And we were able to talk about how our day went and what we saw and things of that nature.... In that sense, we were able to get the gore out of our life. You know, just talking about it right after that, I think that was kind of therapeutic. . . . I think it was the friendship of the unit and being able to talk about it that got me through it.

\section{Reintegration}

The transition home is a time period that can last a few weeks, several months, or sometimes years. This period is characterized by two indistinct, yet overlapping, processes. They are "hanging on" to military friendships and, eventually, realizing that some of the intimacy and trust developed during deployment between military friends are no longer as strong as they used to be. Ironically, this transition home is when maintaining the strong bond with military friends would be most beneficial to the men.

Upon their return home, many veterans struggled with their deployment experiences. Steve was in the Army National Guard and served in Iraq. He was subsequently treated for depression and PTSD related to an attack in which someone from his unit was killed by an IED. The attack began a year of relentless enemy contact and combat for Steve. He said that he had close friends in whom he confided but was reluctant to share his deployment experiences with them. When asked why, he shrugged and said, "It's hard to find people to talk to about it. Not everybody understands and some people, you don't want to tell them about certain things." When asked to clarify what he meant by "not everybody understands," he struggled at first to respond and then said-

I don't think they understand that even though you may not be on a mission, you're still extremely stressed out. Every day, you have no clue what's going on either at home or in Iraq. Every day, you wonder if this is going to be my day, and I don't think people understand here because they don't have to really experience some of that. I mean you could say that today is the day I'm going to die because I get in a car accident, but you know it's something people don't think about here. It's just emotions I think that they don't, they don't know.

\section{Hanging On}

For weeks or sometimes months after they returned, some of the men attempted to hold tight to the intimacy of their military friendships. They sought former unit mates, shunning civilian family and friends. They hung out with military friends three or four nights a week at bars and restaurants, had parties or barbecues at home, or took trips to Las Vegas or Disney. This period was characterized by the men avoiding prolonged contact with civilian friends and, in some cases, family members. Of course, some men had no trouble reintegrating into families and 
returned to the routine of seeing military friends only during drill weekends. But others actively maintained military friendships by seeking unit members two or more times a week.

For example, Don said that "hanging out with friends, the guys who you were there with" was an essential part of easing back into civilian society. He felt that returning home lacked the daily structure he had become accustomed to during his year of deployment. He stated-

Over there, you wake up, you go get breakfast, you go to your job, come back, get dinner, go to bed. It's set. Um, and here it's just kind of you don't have anybody telling you what to do, you got to cook for yourself. Drive yourself around ....

Because civilian society lacked "the whole structure thing," he appeared to have re-created some structure by reconnecting with unit buddies. "We pretty much all became alcoholics for a couple weeks. ... It was a month straight that we got home and drank. We went out to the bar every day.” He wasn't sure when he stopped going out every night, but said, "there's a part where you just don't go the bar every night again.” After a month or two, he got "back in the swing of things, just like, just like everything else."

\section{Loss of Military Family}

The realization that civilian friends and family members do not understand and the practical reality of getting "back in the swing of things" are related to the sense of loss immediately after deployment when demobilization "breaks up" the unit. With families and friends awaiting their arrival, returning home often means separating from those with whom the men shared the mundane and extraordinary during their deployment. Michael, who was married at the time of deployment said, "The camaraderie with all my friends on the plane just came to a screeching halt when we came back home, and I realized that I was never going to see those guys again really." Michael's feelings represent one of the most emotionally stressful facts about war: coming home means losing the intimacy with valued friends who have shared the unique strains of combat deployment.

Marine Reservist Matt served as a machine gun operator on a Humvee and was assigned convoy security duty. His unit was ambushed several times, and he was involved in several firefights with the enemy. As with many of the veterans we interviewed, he found it difficult to discuss these experiences with anyone who was not involved in combat. "As far as trying to explain it to my wife, sometimes she's just like tired of hearing the stories and tired of, she's like, she can't, she's never going to really understand." Asked if he found the inability to share his thoughts and feelings about deployment with his family and friends frustrating, he responded, "Yeah, it's frustrating. For sure. I mean, you know, trying to talk to some of my friends and it's just a story to them.” Matt's comparison of his combat experiences with a story told to his family and friends is revealing. Stories are fictional accounts that happen to someone else, disconnected from daily life. "It's not really until it's up in your face, and you're dealing with it, it's not real, it's not reality." Family and friends often "want to know 'What's going on? You know, talk to me. Tell me how you're feeling.' You're not going to understand, I mean, I can't explain it to you.” Matt continued, "It's definitely good to be able to share things with the other people that have experienced the same situation." As he spoke, he appeared to withdraw into himself:

I mean it was tough times, but, you know, you kind of got a bond. And, yeah, we [unit comrades] were at each other a lot but then you kind of miss some of the things you were able to share. You go from hanging out with these guys all the time and then you are not with them anymore. You kind of miss some of these things.

He paused for moment then quietly he said, "I have to get a hold of some of those guys.”

\section{Seeking to Reconnect with Military Family}

The men gravitated toward friendships with veterans. They did not discuss explicitly wanting to form friendship networks that consisted solely of veterans, but apart from their families and a few close predeployment friends, many of the men found that their new friendships were with other veterans of approximately the same age who had been deployed in the same conflict(s). The veterans interviewed for this study generally found new friends informally through chance meetings or sought them out formally as they attempted to reach out to those who understood what they were going through.

\section{Informal Setting}

The benefit of veterans' relationships with each other during the reintegration period came through clearly as Matt reminisced about another Marine he met while on vacation who had served in Iraq during the same time period. These men were not in the same unit, but Matt 
felt they shared a bond because of their deployment to Iraq. They began to share stories and discuss some of the difficulties they faced upon returning home. Matt said he could talk with the man because "even with somebody in the Army or other service, just that military brotherhood that you feel like you can share and they can actually understand what's going on and what you're thinking." Matt and his Marine friend have continued to maintain an email relationship.

\section{Formal Setting}

One obvious place where veterans reconnect is in the Guard or Reserve weekend drills. Matt told of the year that followed deployment and how he looked forward to going to drill. "Being with the other guys, like the Reserves, you know they understand. You may go through the same thing they're going. ... . They're able to share the ideas and kind of help to cope ... with each other." Although they rarely have weighty discussions like those that once took place during deployment, he felt comforted that his friends were there and were available if he needed to talk.

For others, military friendships evolved in settings designed specifically for that purpose, such as in Department of Veterans Affairs (VA) group counseling sessions. Steve attended weekly group sessions as part of his PTSD treatment. He liked the support he received from others who "have been there." Trevor, an Army National Guard veteran of Afghanistan and Iraq, felt the same way when he enrolled in group counseling at the VA. Jobs, kids, parents, and any number of issues that make up daily life are open for discussion in these sessions. Most of all, it is the deployment experience that veterans share:

We had sessions, group sessions, where they put us together and we talked. So . . . venting out was a really good thing that we did. These group sessions that we had in the VA with other soldiers from different units, it was not all of our one unit. It was everybody there, from different units, different experiences, we all shared those experiences. We saw, I saw how he went through, how she went through. They see how I went through, what we did, what they did. So we all discuss and we found like a nice attachment, you know.

This attachment helps to reorient veterans to the strains of the civilian society. For Trevor, it was the feeling of knowing that other veterans are experiencing the same problems and have an "interest of what you do, what you did, how you lived there, how you live here. It really plays a good role in your comeback to the civilian life. It makes you feel welcome.” He went on to state that the group sessions put him in touch with other veterans who knew what he was going through. In particular, he felt his family was not giving him enough time to himself. "I just wanted to come back and sit down and watch a movie and just relax. But I have everybody like 'ggggg' (makes a clawlike gesture with his hands) 'come on, get away from me." He could complain to other veterans about his family members without hurting their feelings. Other veterans shared advice and examples of how they handled similar situations. The result, for Trevor, was that "when we come to have the touch of the civilian world, we were mostly ready for it."

\section{DISCUSSION}

The importance of military friendships in dealing with the terror, horror, sadness, boredom, and tedium of deployment was a strong recurring theme in all the interviews in this study. The men talked about the connection to other military members as a "brotherhood" or "camaraderie" or the "bonds of war." However, they referred to their friendships clearly; all of them had developed close, even intimate, friendships during deployment. These friendships were instrumental in bringing humor to stressful events, providing emotional support when the men were homesick, or provided a shoulder to lean on after the terror of enemy engagement. Sometimes, friends just provided a needed distraction from the tedium of long hours of duty. This is not to say that these men were friends with everyone in their unit; as with any large group, personality conflicts clearly existed. But on whole, these narratives clearly express the support that military friendships provided when the servicemembers were overcome by the strain of deployment.

Military unit members should be thought of as a resource for family reintegration; clinicians should build on the interpersonal and deep connections veterans have with other veterans. An emergent approach to therapy within the VHA regarding the effect of veteran support groups certainly accounts for these connections and so do volunteer and nonprofit organizations, such as Veterans Helping Veterans and the Wounded Warrior Project. Both of these organizations are based on the idea that veterans feel more comfortable supporting and receiving support from other veterans. The concept of mutual support that 
motivates these activities is an extension of servicemember training and shared experiences. The activities touch on what is missing for many veterans when they return home: the social and emotional support of members of the military unit.

This lack of emotional and social support is more pronounced for members of the National Guard and Reserves than for Active Duty personnel. Active Duty personnel typically return to a duty station on a military base and continue daily assembly where they have regular and sustained contact with unit members and military friends. Members of Guard and Reserve units typically see their units scattered throughout civilian society. Retaining connections with military friends outside the monthly unit assembly requires additional time and effort. With families and civilian jobs that demand attention, finding the time can be difficult. Differences in the role of military friendships of Guard and Reserve versus Active Duty personnel in reintegration and the barriers in maintaining those friendships remain areas open for investigation.

The efficacy of using veterans to reach out to veterans is based on the military strategy that aids warriors in grieving the loss of fellow unit members. In the current wars in Iraq and Afghanistan, company-, regimental-, or battalion-level memorial services for those killed in theater are common. Expressing grief in public is acceptable at these mass ceremonies. The message is that in life and death, the warrior finds succor in military camaraderie and can do so openly and without embarrassment. Back home, separated from the unit but reunited with the family, the warrior is subjected to civilian codes of masculinity that disapprove of men crying. Culturally dominant forms of adult masculinity discourage expressions of most emotions other than anger [37-38]. Few men or women who have not been deployed in combat can understand what the warrior has endured. This lack of understanding creates an environment where the veteran may feel isolated and is reluctant to share his or her thoughts and feelings with anyone except those who will understand: former and current military members. This may explain why recently deployed veterans are said to be physically present but psychologically absent from the family [8]. Family members may resent the intimacy that many veterans share with their military friends [39], just as a family member's lack of understanding of the importance of military friendships can cause resentment in veterans [11]. The resentment can grow out of the loss of intimate relationships with former unit members and the loss of someone who understands.

Recent research on postcombat mental health assessments shows that a significant increase in mental health problems occurs 120 days past deployment and beyond [40]. Future reintegration interventions could routinely provide veterans with access to other veterans during the reintegration process. Although problems associated with deployment can last for years [11], regular and routine unit reunions promise to provide veterans with a space where many would feel safe and comfortable sharing deep emotional pain related to military trauma [24].

We noted that while some men appeared to avoid family in favor of military friends, others saw friends only during drill weekends. In this sample, the men who quickly returned to the routine of seeing friends during weekend drill returned to jobs that had some associated authority and power, such as manager, police officer, or human resources coordinator. Men who worked low-paid hourly wage jobs were more likely to work actively to maintain military friendships outside of drill for longer time periods. One explanation might be that, even among the lowest ranks, military personnel have real authority and power while deployed. They have the authority to demand that enemy combatants cease hostility, and they possess the power (i.e., both the means and right) to use lethal force if their demands are not met. Returning home strips them of these resources. These resources are central components of masculinity; when access to power and authority are not available in jobs, military friendships can provide a vivid reminder, linking them to the power and authority they once had. On the other hand, military friendships may offer a welcome distraction from the mundane routine of low-paid jobs. Whatever the case, the meaning of work in facilitating or impeding reintegration is a topic worth exploring further.

\section{Clinical Considerations}

The bond between military friends can provide much needed positive support during the reintegration and postdeployment transition; therefore, considering how clinicians can encourage the strengthening of these social networks in the lives of returning servicemembers is important. The first critical step for clinicians to take is to obtain information during intake about the servicemember's social support system that explores the extent and makeup of their support network. Servicemembers who report having positive military friendships may benefit 
from the provision of psychoeducation concerning the importance of social supports during the reintegration process. This approach would help reiterate for servicemembers and clinicians the saliency of these relationships. Another clinical approach is to engage the servicemembers in reminiscing about the different experiences they had with persons in their unit while they were deployed. This exercise aims to rekindle a sense of community and reminds servicemembers that there are others they care about (and who presumably care about them) who have had similar experiences. It also subtly encourages them to follow up with military friends. Should servicemembers express that they have reached out but failed to rekindle military friendships, barriers to reconnection can be a topic for discussion and problem solving during counseling. Servicemembers who express a desire to reconnect with military friends but lack motivation or do not reconnect out of fear of rejection provide clinicians with information regarding a course of treatment.

One major barrier may be resource constraints, such as time or money, which may prevent the servicemember from being able to physically visit military friends. If this is the case, the servicemember can be encouraged to think about ways she or he can maintain relationships through available technologies, such as email, telephone, or letters. Mental health providers can also encourage the servicemember to seek out social connections through venues like military-related therapy/support groups, local and national veterans organizations, or a VA medical center (e.g., volunteering). Clinicians need to maintain a current list of these resources to offer the servicemember to increase the likelihood of following through. For those in intimate relationships, another challenge to reconnection may be encountered if the servicemember's partner disapproves of continued contact with former unit mates. This intimate partner's disapproval is an area for clinical intervention; the clinician can offer couples therapy to discuss possible solutions. As an exercise in overcoming a known source of partner strain, therapy offers a unique teaching moment in which clinicians can help strengthen couple resilience.

When servicemembers maintain few or no established friendships within either the civilian or the military populations, clinicians can discuss with the veteran why that might have occurred. Some servicemembers may feel as if they have nothing in common with someone who has not served in operational environments. Servicemembers may disengage from interactions with former friends to decrease their feelings of awkwardness or alienation. Disengagement from military friendships may also be an issue, since some deployed veterans avoid veterans to forget traumatic or stressful experiences. Former military friends may also evoke memories of nondeployment-related trauma, such as military sexual trauma or blatant racial discrimination. Clinicians should be aware of any number of factors that may hinder the maintenance of military friendships. Whatever the level of connection, military friendships offer a unique resource for clinicians to help servicemembers find a sense of normalcy after deployment.

\section{Limitations of Study}

The main limitation of this research is that standpoint retrospective interviews only capture a snapshot of the participant's experiences. This approach provides a good picture of the qualitative nature of the deployment and reintegration experience but does not allow researchers to track change over time. Many of the men who expressed a reluctance to reach out to civilian family and friends have likely begun to share their deployment experiences as time passes. A longitudinal approach would provide a fuller picture of when and how veterans begin to share deployment experiences with civilians and with whom a veteran may first share his or her experiences. Time, distance, and resources are likely to reduce contact and interaction with military friends. A longitudinal approach would be more appropriate in determining when this friendship "drift" begins, and how it progresses, or how individuals avert it and reestablish friendship ties.

Although we do not consider this a limitation, interviews with Active Duty (i.e., full-time) military personnel may provide a slightly different picture of military friendships. The main difference between Active Duty and Reserve component servicemembers is that Active Duty personnel typically see and interact with one another daily; many spend most of their waking and sleeping hours together. Reservists and National Guard servicemembers may only interact during the monthly training that occurs over the weekend. Of course, this situation changes during deployment, but the history and strength of ties between Active Duty personnel before deployment may elicit different outcomes in terms of veterans' ease in sharing deployment experiences with nonmilitary civilians.

Finally, this study was designed to explore men's experiences with deployment and reintegration. An obvious limitation to understanding the importance of military friendships is the omission of female veterans' experiences. We pointedly state that the literature and 
data presented here do not reflect that female veterans' voices are less valuable than male veterans' voices. Future work should include a mixed sex sample.

\section{CONCLUSIONS}

The importance of military friendships in dealing with the terror, horror, sadness, boredom, and tedium of deployment was evident in how the men in this study talked about their deployment experiences. These personal connections have important implications for reintegration policy. Military friendships may be important during postdeployment reintegration and may be an important clinical resource for clinicians in helping veterans transition into civilian society.

\section{ACKNOWLEDGMENTS}

\author{
Author Contributions: \\ Study concept and design: R. Hinojosa. \\ Acquisition of data: R. Hinojosa. \\ Analysis and interpretation of data: R. Hinojosa, M. S. Hinojosa. \\ Drafting of manuscript: R. Hinojosa, M. S. Hinojosa. \\ Critical revision of manuscript for important intellectual content: \\ R. Hinojosa. \\ Statistical analysis: M. S. Hinojosa. \\ Obtained funding: R. Hinojosa. \\ Administrative, technical, or material support: R. Hinojosa, \\ M. S. Hinojosa.
}

Financial Disclosures: The authors have declared that no competing interests exist.

Funding/Support: This material was based on work supported by Marquette University, Summer Faculty Fellowship Program, grant HR1606 (Ramon Hinojosa, Principle Investigator) titled "Home From War: Transitions From the Military to the Civilian Community Post- OEF/ OIF Deployment.” Salary support for analyzing data and writing the manuscript was provided by the VA Rehabilitation Outcomes Research Center and the North Florida/South Georgia Veterans Health System.

Additional Contributions: We would like to thank Virginia Hessels for her editorial assistance.

Institutional Review: The institutional review board of Marquette University approved the study.

Participant Follow-Up: The authors do not plan to inform participants of the publication of this study because of a lack of participant contact information.

\section{REFERENCES}

1. Goff BS, Smith DB. Systemic traumatic stress: The couple adaptation to traumatic stress model. J Marital Fam Ther.
2005;31(2):145-57. [PMID: 15974055]

http://dx.doi.org/10.1111/j.1752-0606.2005.tb01552.x

2. Westerink J, Giarratano L. The impact of posttraumatic stress disorder on partners and children of Australian Vietnam veterans. Aust N Z J Psychiatry. 1999;33(6):841-47.

[PMID: 10619210]

http://dx.doi.org/10.1046/j.1440-1614.1999.00638.x

3. Goff BS, Crow JR, Reisbig AM, Hamilton S. The impact of individual trauma symptoms of deployed soldiers on relationship satisfaction. J Fam Psychol. 2007;21(3):344-53.

[PMID: 17874919]

http://dx.doi.org/10.1037/0893-3200.21.3.344

4. Monson CM, Taft CT, Fredman SJ. Military-related PTSD and intimate relationships: From description to theory-driven research and intervention development. Clin Psychol Rev. 2009;29(8):707-14. [PMID: 19781836]

http://dx.doi.org/10.1016/j.cpr.2009.09.002

5. Galovski T, Lyons JA. Psychological sequelae of combat violence: A review of the impact of PTSD on the veteran's family and possible interventions. Aggress Violent Behav. 2004;9(5): 477-501. http://dx.doi.org/10.1016/S1359-1789(03)00045-4

6. Monson CM, Guthrie KA, Stevens S. Cognitive-behavioral couples' treatment for posttraumatic stress disorder. Behav Ther. 2003;26:393-401.

7. Monson CM, Taft CE. PTSD and intimate relationships. PTSD Res Q. 2005;16(4):1-8.

8. Karney BR, Crown JS. Families under stress: An assessment of data, theory, and research on marriage and divorce in the military. Santa Monica (CA): RAND Corporation; 2007.

9. Defense Manpower Data Center. Profile of currently deployed personnel, December 2009. Washington (DC): Department of Defense; 2010.

10. Defense Manpower Data Center. Deployment by family status. Washington (DC): Department of Defense; 2010.

11. Hosek J, Kavanagh J, Miller L. How deployments affect service members. Santa Monica (CA): RAND Corporation; 2006.

12. King LA, King DW, Fairbank JA, Keane TM, Adams GA. Resilience-recovery factors in post-traumatic stress disorder among female and male Vietnam veterans: Hardiness, postwar social support, and additional stressful life events. J Pers Soc Psychol. 1998;74(2):420-34. [PMID: 9491585] http://dx.doi.org/10.1037/0022-3514.74.2.420

13. Newby JH, Ursano RJ, McCarroll JE, Lui X, Fulleron CS, Norwood AE. Postdeployment domestic violence by U.S. Army soldiers. Mil Med. 2005;170(8):643-47. [PMID: 16173201]

14. Rentz ED, Marshall SW, Loomis D, Casteel C, Martin SL, Gibbs DA. Effect of deployment on the occurrence of child maltreatment in military and nonmilitary families. Am J 
Epidemiol. 2007;165(10):1199-1206. [PMID: 17329716] http://dx.doi.org/10.1093/aje/kwm008

15. Angrist JD, Johnson JH. Effects of work-related absences on families: Evidence from the Gulf War. Industrial Labor Relations Rev. 2000;54:41-58. http://dx.doi.org/10.2307/2696031

16. Schumm WR, Bell DB, Gade PA. Effects of military overseas peacekeeping deployment on marital quality, satisfaction, and stability. Psychol Rep. 2000;87(3 Pt 1):815-21.

[PMID: 11191394$]$ http://dx.doi.org/10.2466/PR0.87.7.815-821

17. Stellman JM, Stellman SD, Sommer JF. Social and behavioral consequences of the Vietnam experience among American Legionnaires. Environ Res. 1988;47(2):129-49. [PMID: 3263268] http://dx.doi.org/10.1016/S0013-9351(88)80038-0

18. Gamache G, Rosenheck R, Tessler R. Military discharge status of homeless veterans with mental illness. Mil Med. 2000;165(11):803-8. [PMID: 11143423]

19. Gamache G, Rosenheck R, Tessler R. The proportion of veterans among homeless men: A decade later. Soc Psychiatry Psychiatr Epidemiol. 2001;36(10):481-85. [PMID: 11768845] http://dx.doi.org/10.1007/s001270170012

20. Gamache G, Rosenheck R, Tessler R. Overrepresentation of women veterans among homeless women. Am J Public Health. 2003;93(7):1132-36. [PMID: 12835198] http://dx.doi.org/10.2105/AJPH.93.7.1132

21. Rosenheck R, Fontana A. A model of homelessness among male veterans of the Vietnam generation. Am J Psychiatry. 1994;151(3):421-27. [PMID: 8109652]

22. Higate PR. Theorizing continuity: From military to civilian life. Armed Force Soc. 2001;27(3):443-60. http://dx.doi.org/10.1177/0095327X0102700306

23. Shakespeare W. King Henry V: Act IV, Scene 3, lines 65-68.

24. Sherman N. Stoic warriors: The ancient philosophy behind the military mind. New York (NY): Oxford University Press; 2005.

25. Little R. Friendships in the military community. Research in the interweave of social roles: Friendship. 1981;2:221-35.

26. Shils EA, Janowitz M. Cohesion and disintegration in the Wehrmacht in World War II. Public Opin Q. 1948;12(2): 280-315. http://dx.doi.org/10.1086/265951

27. Stouffer SA, Lumsdaine AA, Harper Lumsdaine M, Williams RMJ, Smith MB, Janis IL. The American Soldier: Combat and its aftermath. Princeton (NJ): Princeton University Press; 1949.

28. Sledge EB. With the old breed at Peleliu and Okinawa. New York (NY): Oxford University Press; 1990. p. 99.

29. Mental Health Advisory Team VI. Mental Health Advisory Team VI Report: Operation Iraqi Freedom 07-09. Wash- ington (DC): U.S. Army Medical Department Army Medicine; 2009.

30. Bliese PD. Social climates: Drivers of soldier well-being and resilience. In: Britt TW, Castro CA, Adler AB, editors. Military life: The psychology of serving in peace and combat. Westport (CT): Praeger Security International; 2006. p. 213-34.

31. Bliese P, Castro CA. The solider adaptation model (SAM): Applications to peacekeeping research. In: Britt T, Adler AB, editors. The psychology of the peacekeeper. Westport (CT): Praeger Publishers; 2003. p. 185-204.

32. Cohen S, Wills TA. Stress, social support, and the buffering effect. Psychol Bull. 1985;98:310-57.

http://dx.doi.org/10.1037/0033-2909.98.2.310

33. Holstein JA, Gubrium JF. The active interview. Thousand Oaks (CA): Sage Publications; 1995.

34. Glaser BG, Strauss AL. The discovery of grounded theory: Strategies for qualitative research. Chicago (IL): Aldine Publishers; 1967.

35. Strauss AL, Corbin JM. Basics of qualitative research: Grounded theory, procedures, and techniques. Newbury Park (CA): Sage Publications; 1990.

36. Lincoln YS, Guba EG. Naturalistic inquiry. Newbury Park (CA): Sage Publications; 1985.

37. Connell R. Masculinities. Berkeley (CA): University of California Press; 1995.

38. Connell R. Gender and power: Society, the person, and sexual politics. Stanford (CA): Stanford University Press; 1987.

39. Musheno MC, Ross SM. Deployed: How reservists bear the burden of Iraq. Ann Arbor (MI): University of Michigan Press; 2008.

40. Bliese PD, Wright KM, Adler AB, Thomas JL, Hoge CW. Timing of postcombat mental health assessments. Psychol Serv. 2007;4(3):141-48.

http://dx.doi.org/10.1037/1541-1559.4.3.141

Submitted for publication August 13, 2010. Accepted in revised form April 22, 2011.

This article and any supplementary material should be cited as follows:

Hinojosa R, Hinojosa MS. Using military friendships to optimize postdeployment reintegration for male Operation Iraqi Freedom/Operation Enduring Freedom veterans. J Rehabil Res Dev. 2011;48(10):1145-58.

DOI:10.1682/JRRD.2010.08.0151

ResearcherID: Ramon Hinojosa, PhD: F-3916-2011

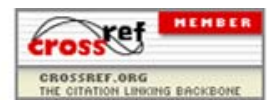


